\title{
Reproduction performance of cows with single, twin and triplet calves
}

\author{
Anna Sawa, Mariusz Bogucki, Sylwia Krężel-Czopek \\ University of Technology and Life Sciences, Department of Cattle Breeding, \\ Bydgoszcz, Poland \\ Received February 17, 2012 \\ Accepted July 16, 2012
}

\begin{abstract}
The aim of this study was to analyse data on 74,081 calvings, subsequent lactation performance and culling of 23,588 Black-and-White cows improved with Holstein-Friesians. The animals represented the active population in Pomerania and Kujavia, first calved in 2000 and 2001, and were culled before the end of 2008. Frequency of calvings, which averaged $1.5 \%$ for twin births and just $0.02 \%$ for triplet births, increased with age of cow and also with increasing milk yield in the preceding lactation. Performance results showed that mothers of twins were superior to mothers of single calves in terms of milk yield (1.3 $\mathrm{kg}$ milk/day milking). Despite the greater perinatal mortality of twins and triplets, multiple pregnancies gave rise to a greater number of calves compared to single pregnancies. However, multiple pregnancies were accompanied by adverse effects such as increased proportion of complications requiring human assistance, mechanical assistance and veterinary intervention $(1.2 \times$ more $)$. Fertility of the cows deteriorated after multiple pregnancies, with particularly unfavourable indicators of fertility found for triplet births, decreased chance of survival to the next calving, and increased culling rates in cows, especially due to udder diseases, infertility, reproductive diseases, old age, metabolic and gastrointestinal diseases, and locomotor system diseases. It was found that the increasing milk yield was paralleled by the increasing proportion of multiple pregnancies. This has highlighted the need for early and reliable diagnosis and management of twin pregnancies, which is supposed to facilitate parturition and ensure survival of calves.
\end{abstract}

Multiple pregnancy, yield, fertility

Cattle are a monofoetal species with occasional multiple pregnancies which result in the birht of a greater number of calves (most often two). Studies conducted in Poland indicate that twins account for 1 to 4\% of calves born (Skrzypek et al. 1989; Kuźma and Kuźma 1994; Wielgosz et al. 1999; Sawa 2001). According to Des Coteaux et al. (2010) and López-Gatius and Hunter (2005), twin pregnancies are estimated to form about $10 \%$ of all pregnancies in dairy cattle (with a positive correlation between milk yield and multiple pregnancies), but are much less frequent in beef cattle. Multiple pregnancies have been given considerable study but researchers vary in their opinions. Most often attention is drawn to the fact that multiple pregnancies have negative effects on increased predisposition for abortion, dystocia and post partum disorders including placental retention, metritis, displaced abomasum, ketosis and fatty liver, as well as lengthening of the calving interval and increased culling of cows that gave birth to twins (Nielen et al. 1989; Kirkpatrick 2002; López-Gatius and Hunter 2005; Des Coteaux et al. 2010; Max 2011). This has highlighted the need for early and reliable diagnosis and management of twin pregnancies, which is supposed to facilitate parturition and ensure survival of calves (Nielen et al. 1989; Echternkamp and Gregory 1999; Kirkpatrick 2002; López-Gatius and Hunter 2005; Des Coteaux et al. 2010).

The aim of the study was to analyse the course of single and multiple births, subsequent milk and reproductive performance, and reasons for culling, based on extensive data on performance tested cows from the Kujawsko-Pomorskie province (about 10\% of the performance recorded population of cows in Poland).

Address for correspondence:

Anna Sawa

Department of Cattle Breeding

University of Technology and Life Sciences

Phone: 0523749710

Mazowiecka 28, 85-084 Bydgoszcz, Poland

http://actavet.vfu.cz/ 


\section{Materials and Methods}

Data for the study were obtained from SYMLEK database and concerned 74,081 calvings and subsequent milk and reproductive performances, and reasons for culling 23,588 Black-and-White cows improved by HolsteinFriesians. The animals represented the active population in Pomerania and Kujavia province, first calved in 2000 and 2001, and were used for milking or culled before the end of 2008.

Analysis of variance was used to evaluate the effect of type of birth (single, twin, triplet) on subsequent milk (days in milk, kg milk) and reproductive performance (length of calving interval (CI), reproductive rest period (RP), service period (SP), number of inseminations (II) and first insemination success). Significant differences $(P \leq 0.1)$ were determined using the Scheffe test (SAS 2010).

Chi square test of independence was used to analyse the incidence of single, twin and triplet births depending on the age of the cow (first-calving heifers, multiparous cows) and, for multiparas, depending on milk yield in the previous lactation $(\leq 5000,5001-7000,>7000 \mathrm{~kg})$. Chi square test was also used to analyse the effect of single, twin and triplet pregnancy on the course of parturition according to SYMLEK: natural (without human assistance), assisted (human or mechanical assistance), difficult (veterinary intervention) and very difficult (caesarean section or embryotomy). The calculations were made depending on the type of birth (single, multiple), the percentage of production cycles interrupted due to selling or culling (taking account of the reasons according to the SYMLEK system: low milk yield, udder diseases, infertility, reproductive diseases, infectious diseases (including leukaemia), old age, metabolic and gastrointestinal diseases, respiratory diseases, diseases of the locomotor system, accidents, and others). The calculations distinguished single and multiple births. Because of the small number of triple births $(n=5)$, they were combined with twin births.

\section{Results}

Analysis of the results presented in Table 1 shows that twin births accounted for $1.5 \%$, and triple births for only $0.02 \%$ of all births in the population under study. The proportion of multiple births was greater for multiparous cows than for first-calf heifers. The increasing milk yield of multiparas was paralleled by the increasing proportion of twin births (from $1.59 \%$ to $2.42 \%$ ).

Multiple pregnancies resulted in a decreased proportion of easy calvings and an increased proportion of complications requiring human assistance, mechanical assistance

Table 1. Effect of age and milk production in previous lactation on proportion of single and multiple births in cows.

\begin{tabular}{|c|c|c|c|c|c|c|c|c|}
\hline & & \multicolumn{7}{|c|}{ Number of births } \\
\hline & & \multirow{2}{*}{$\begin{array}{c}\text { Total } \\
\mathrm{n} \\
\end{array}$} & \multicolumn{2}{|l|}{ Single } & \multicolumn{2}{|l|}{ Twin } & \multicolumn{2}{|l|}{ Triplet } \\
\hline & & & $\mathrm{n}$ & $\%$ & $\mathrm{n}$ & $\%$ & $\mathrm{n}$ & $\%$ \\
\hline Factor & & 74081 & 72956 & 98.48 & 1112 & 1.50 & 13 & 0.02 \\
\hline Pregnancy number & 1 & 22545 & 22463 & 99.64 & 81 & 0.36 & 1 & 0.00 \\
\hline$\left(\chi^{2}=369^{A}\right)$ & $\geq 2$ & 51536 & 50493 & 97.98 & 1031 & 2.00 & 12 & 0.02 \\
\hline Milk (kg) in & $\leq 5000$ & 13280 & 13065 & 98.38 & 211 & 1.59 & 4 & 0.03 \\
\hline previous lactation & $5001-7000$ & 19944 & 19564 & 98.09 & 367 & 1.89 & 4 & 0.02 \\
\hline$\left(\chi^{2}=30^{\mathrm{A}}\right)$ & $>7000$ & 18312 & 17864 & 97.55 & 444 & 2.42 & 4 & 0.02 \\
\hline
\end{tabular}

${ }^{\mathrm{A}}$ significant at $P \leq 0.1$

Table 2. Effect of single, twin and triplet pregnancy on the course of calving $\left(\chi^{2}=101.25^{\mathrm{A}}\right)$.

\begin{tabular}{lccc}
\hline \multirow{2}{*}{ Type of calving } & \multicolumn{3}{c}{ Course of calving depending on type of pregnancy (\%) } \\
\cline { 2 - 4 } & Single pregnancy & Twin pregnancy & Triplet pregnancy \\
\hline Easy & 44.98 & 30.49 & 30.77 \\
Human assistance & 54.49 & 63.35 & 69.23 \\
Difficult & 0.51 & 1.08 & 0.00 \\
Dystocia & 0.02 & 0.09 & 0.00 \\
\hline
\end{tabular}

${ }^{\text {A }}$ significant at $P \leq 0.1$ 
Table 3. Milk and reproductive performance of cows per production cycle after giving birth to one calf, twins and triplets.

\begin{tabular}{lrrr}
\hline Performance trait & \multicolumn{3}{c}{ Type of pregnancy } \\
\cline { 2 - 4 } & Single & Twin & Triplet \\
\hline Number & 72956 & 1112 & 13 \\
Days in milk & $333^{\mathrm{A}}$ & $322^{\mathrm{A}}$ & 374 \\
Kg milk per lactation & $6219^{\mathrm{a}}$ & $6434^{\mathrm{a}}$ & 7097 \\
Calving interval (days) & $416^{\mathrm{A}}$ & $430^{\mathrm{A}}$ & 487 \\
Rest period (days) & $87^{\mathrm{A}}$ & $96^{\mathrm{A}}$ & 104 \\
Service period (days) & 45 & 52 & 93 \\
Insemination index & $1.98^{\mathrm{a}}$ & 2.10 & $3.29^{\mathrm{a}}$ \\
First insemination success (\%) & 49.11 & 45.76 & 28.57 \\
Length of pregnancy (days) & $279^{\mathrm{A}}$ & $276^{\mathrm{A}}$ & 275 \\
Number of calves born alive & 0.97 & 1.87 & 2.69 \\
Proportion of production cycles followed by calving (\%) & 72.26 & 59.29 & 61.50 \\
\hline
\end{tabular}

${ }^{\mathrm{A}}$ means within lines followed by the same letters differ significantly at $P \leq 0.01,{ }^{\mathrm{a}}$ means within lines followed by the same letters differ significantly at $P \leq 0.05$

or veterinary intervention (Table 2). Two-thirds of twin births required human assistance, of which $1.1 \%$ required veterinary intervention. Fifty-four percent of single-calving cows required human assistance, of which only $0.5 \%$ required veterinary intervention.

Performance results (Table 3) showed that mothers of twins were superior to mothers of single calves in terms of milk yield. Fertility of the cows deteriorated after multiple pregnancies, with particularly unfavourable indicators of fertility found for triplet births. The number of calves born alive was higher among mothers of twins and triplets compared to mothers of single-born calves. Multiple pregnancies considerably decreased the chance of survival until the next calving (Table 3 ) and increased the culling rate (Table 4). When analysing the reasons for culling cows from the herds, it was found that multiple births gave rise to a greater proportion of cows culled due to udder diseases, infertility, reproductive

Table 4. Culling patterns (according to SYMLEK) in cows after single and multiple pregnancy $\left(\chi^{2}=28.26^{\mathrm{A}}\right)$

\begin{tabular}{|c|c|c|}
\hline \multirow[t]{2}{*}{ Reasons for culling } & \multicolumn{2}{|c|}{$\begin{array}{l}\text { Proportion of production cycles interrupted due to } \\
\text { selling or curling depending on type of pregnancy }\end{array}$} \\
\hline & Single pregnancy $(\%)$ & Multiple pregnancy $(\%)$ \\
\hline Production cycles interrupted due to selling or culling (n, \%) & $20548(27.74 \%)$ & $458(40.71 \%)$ \\
\hline Sold for further breeding & 13.81 & 9.61 \\
\hline Low yield & 3.82 & 2.62 \\
\hline Udder diseases & 11.83 & 13.54 \\
\hline Fertility and reproductive diseases & 34.58 & 37.99 \\
\hline Infectious diseases (leukaemia) & 2.79 & 1.97 \\
\hline Old age & 1.09 & 1.31 \\
\hline Metabolic and digestive diseases & 2.06 & 3.93 \\
\hline Respiratory diseases & 0.12 & 0.00 \\
\hline Diseases of the locomotor system & 3.22 & 4.37 \\
\hline Accidents & 21.27 & 17.25 \\
\hline Other & 5.14 & 7.42 \\
\hline
\end{tabular}

${ }^{\mathrm{A}}$ significant at $P \leq 0.1$ 
diseases, old age, metabolic and gastrointestinal diseases, and diseases of the locomotor system.

\section{Discussion}

The results obtained in our study for multiple births falls within the range estimated by other authors (Skrzypek et al. 1989; Kuźma and Kuźma 1994; Wielgosz et al. 1999; Saw a 2001). In our study, the chi square test showed a highly significant effect $(P \leq 0.1)$ of age and production level on the incidence of single, twin and triplet births, with the greatest variation found within age groups, from $0.36 \%$ (first-calving heifers) to $2 \%$ (multiparous cows) in the case of twin births. These observations are consistent with those of other authors (Kuźma and Kuźma 1994; Wielgosz et al. 1999; Sawa 2001; Max 2011) who found that twins are very rarely born at first calving. Kuźma and Kuźma (1994) attributed this fact to increased mortality of one foetus in the twin pregnancy of heifers as a result of the increased protein and energy requirement by the developing mother's body and twin foetuses.

In multiparous cows, the increasing milk yield was paralleled by the increasing proportion of twin births. According to Bierman et al. (2010), selection for high milk yield favours multiplication of genes in a population that may also, to a certain extent, promote a predisposition to double ovulations, which increase the likelihood of twin pregnancy (Max 2011). High milk yield has been shown to affect the incidence of double ovulation. Cows producing $31.1 \mathrm{~kg}$ of milk had $6.9 \%$ of double ovulations, and in cows yielding 56.7 $\mathrm{kg}$ this proportion was as high as $20.2 \%$ (Fricke and Wiltbank 1999).

The results obtained in our study suggest that multiple pregnancies can be regarded as one of the reasons for difficult births. Kuźma and Kuźma (1994) reported that abortions and premature births and difficult births are twice as frequent in twin-calving cows as in cows carrying single pregnancies. According to Echternkamp et al. (2007), the increased incidence of calving complications compared to single births resulted from abnormal foetal presentation at delivery (especially abnormal foetal posture and position) or simultaneous impaction of the presenting parts of both foetuses in the reproductive tract. Excessive total weight of foetuses may also prove an obstruction during parturition (NałęczTarwacka et al. 2011). Early diagnosis of multiple pregnancies, proper veterinary care and treatments, and especially appropriate nutrition and housing of pregnant cows may soften the undesirable consequences of multiple pregnancies (Kuźma and Kuźma 1994; Max 1996).

Twin pregnancies were more frequent in cows with higher milk production levels in the first lactation. This confirms the predominance of mothers of twins over mothers of single calves, reported by other authors (Wielgosz et al. 1999; Sawa 2001). A review paper summarizing the findings of many authors (Skrzypek et al. 1989) shows that the effect of twin pregnancy on the milk yield of cows is highly complex and depends on the nutritional requirements of pregnant cows, the level of oestrogen hormones, progesterone, placental lactogen, prolactin, and the dry length period. Kuźma and Kuźma (1994) pointed to nutrition as the main factor determining the effect of twin pregnancy on milk yield.

Twin pregnancy was 3 days shorter, and triplet pregnancy 4 days shorter than single pregnancy (Table 3). Meanwhile, Echternkamp and Gregory (1999) reported that twin pregnancies were 5.7 days shorter $(P \leq 0.01)$ than single pregnancies. According to Max (1996), placental immaturity due to shortened pregnancy and low oestrogen concentration as well as post partum uterine atonia are the main reasons for post partum complications. Poorer fertility after multiple calvings may result not only from dystocia, which causes post partum complications such as placental retention and inflammation of the reproductive tract (Kuźma and Kuźma 1994), but also from the fact that higher yielding cows were 
the mothers of twins, and the results of recent observations suggest a negative effect of increasingly high milk yield on cow fertility.

The available literature (Sawa 2001; Nałęcz-Tarwacka et al. 2011) indicates that twins are less viable. Our results confirm higher perinatal mortality of the twins, but despite the losses 1.87 live calves were obtained from a twin calving compared to only 0.97 from a single calving (Table 3). Even if we account for the fact that heifers from differentsex pregnancies are usually infertile (Nałęcz-Tarwacka et al. 2011), from the economic point of view it seems that it is advantageous to produce twin calves, especially when they are intended for fattening.

Multiple pregnancy considerably increased the culling rate of cows (Table 3 and 4), which is consistent with the findings of Max (2011). Analysis of the reasons for culling the cows revealed an economically unfavourable increase in the proportion of cows culled for reasons beyond the breeders' control (udder diseases, infertility, reproductive diseases, metabolic and gastrointestinal diseases, and locomotor system diseases) among mothers of twins and triplets compared to other cows. Attention has long been drawn to the negative consequences of twin pregnancy associated with metabolic disorders, labour complications and postnatal pathology such as placental retention, postparturient metritis, parturient paresis, ketosis, lameness, udder inflammation, and ovarian dysfunction (Max 1996, 2011). Our study also showed that voluntary culling by the breeder (animals sold for further breeding, low milk yield) was lower among mothers of twins and triplets than in other cows. The lower proportion of cows culled due to low milk yield confirms the higher milk yield of mothers of twins and triplets compared to mothers of single calves, as shown in Table 3. The higher proportion of cows culled due to old age is consistent with a tendency to the increasing proportion of multiple births with the age of the cow (Table 1). In summary, multiple pregnancies resulted in a greater number of calves born compared to single pregnancies. However, multiple pregnancies were accompanied by adverse effects such as increased proportion of complications requiring human assistance, mechanical assistance and veterinary intervention, lower fertility, decreased chance of survival to the next calving, and increased culling rates in cows, especially due to udder diseases, infertility, reproductive diseases, old age, metabolic and digestive diseases, and locomotor system diseases.

\section{References}

Bierman CD, Kim E, Shi XW, Weigel K, Jeffery Berger P, Kirkpatric BW 2010: Validation of whole genome linkage-linkage disequilibrium and association results, and identification of markers to predict genetic merit for twinning. Anim Genet 41: 406-416

Des Coteaux L, Gnemmi G, Colloton J 2010: Practical atlas of ruminant and camelid reproductive ultrasonography. Blackwell Publishing: 1-244

Echternkamp SE, Gregory KE 1999: Effects of twinning on gestation length, retained placenta, and dystocia. J Anim Sci 77: 39-47

Echternkamp SE, Thallman RM, Cushman RA, Allan MF, Gregory KE 2007: Increased calf production in cattle selected for twin ovulations. J Anim Sci 85: 3239-3248

Fricke PM, Wiltbank MC 1999: Effect of milk production on the incidence of double ovulation in dairy cows. Theriogenology 52: 1133-1143

Kirkpatrick BW 2002: Management of twinning cow herds. J Anim Sci 80 (E. Suppl. 2): E14-E18

Kuźma R, Kuźma K 1994: Incidence of multiple births in dairy cows under natural conditions and their effect on parturition, postparturient period and fertility. Prz Hod 9: 1-5

López-Gatius F, Hunter RH 2005: Spontaneous reduction of advanced twin embryos: its occurrence and clinical relevance in dairy cattle. Theriogenology $63: 118-125$

Max A 1996: Twin pregnancy in cattle. Med Wet 52: 85-88

Max A 2011: The fertility of cows after twin parturitions in the herd of high milk yield. Życie Wet 86: 618-619

Nałęcz-Tarwacka T, Palińska K, Grodzki H 2011: Influence of multiple pregnancy on delivery complications and calf mortality. Med Wet 67: 409-411

Nielen M, Schukken YH, Scholl DT, Wilbrink HJ, Brand A 1989: Twinning in dairy cattle: A study of risk factors and effects. Theriogenology 32: $845-862$ 
SAS Institute Inc.: SAS/STAT(r) 9.3 User's Guide. Cary. NC: SAS Institute Inc., 2010

Sawa A 2001: Effect of birth type on performance, fertility and culling of black-and-white cows. Ann Anim Sci 1: $13-24$

Skrzypek R, Baraniak R, Grycz J 1989: Influence of twinning on milk yield, reproductive performance and culling rate of cows as well as on the viability of their calves. Zesz Nauk AR w Poznaniu 38: 83-94

Wielgosz Groth Z, Cieśluk S, Kijak Z, Cichocki M 1999: The frequency of incidence of various types of parturitions and the relationship between the type of the parturition and milk yield. Zesz Nauk PTZ 44: $249-256$ 